\title{
Analysis of gravity and magnetic data along Rumtse-Upshi-Leh- Kardung la and Rumtse-Upshi-Igu-Shakti-Chang la - Durbuk profiles - Presence of ophiolites within Ladakh batholith and suture zones
}

\author{
Rambhatla G Sastry* and Md Israil \\ Department of Earth Sciences, Indian Institute of Technology Roorkee Roorkee-247667, INDIA \\ * For correspondence, email: rgss1fes@iitr.ernet.in
}

Our gravity and magnetic profile data sampled at 1-2 km spacing along Rumtse-Upshi-Leh-Kardung La and Rumtse-UpshiIgu-Shakti-Chang La-Durbuk profiles across Indus formation, Ladakh batholith and Suture zones are analyzed. The gravity data are processed with our variable density Bouguer anomaly computation algorithm. Spectral analysis of gravity data indicates that the high frequency residual anomalies are of shallow origin. A simple modeling of magnetic data indicates that the ophiolites occur as dykes of steep dips at shallow depths within Ladakh batholith and Shyok suture zones. Detailed gravity modeling is not attempted here.

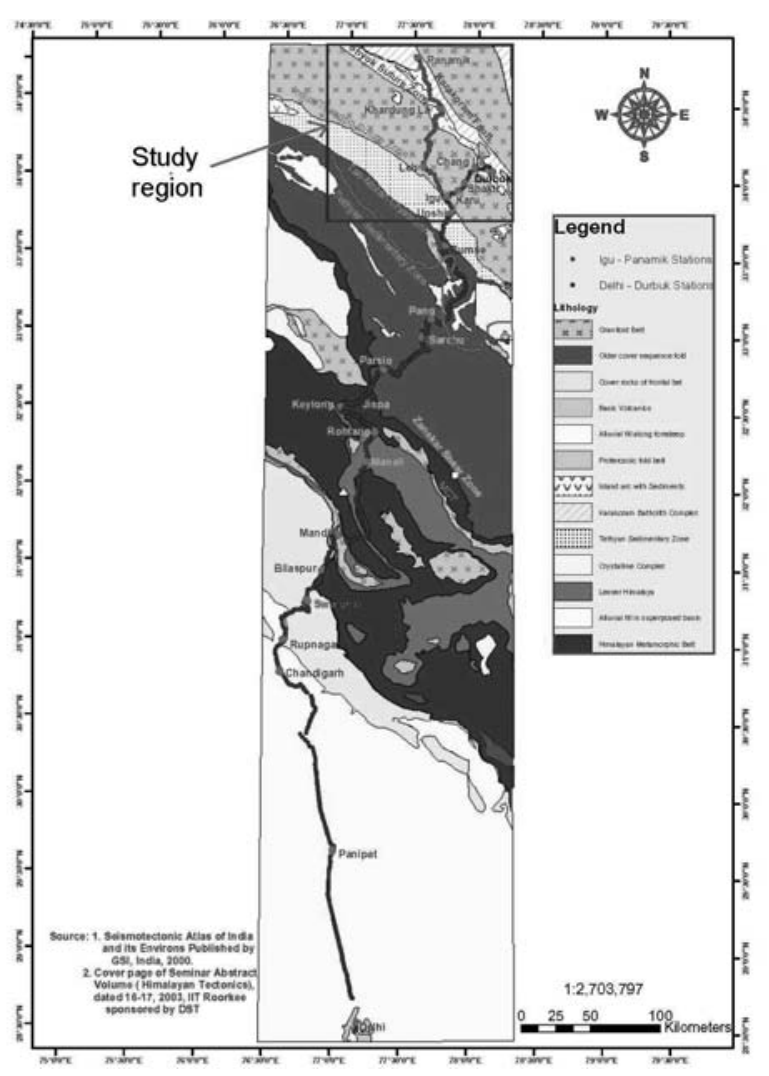

FIGURE 1. The study region is marked with a box in the above map. Both Rumtse-Upshi-Leh-Panamik and Rumtse-Upshi-Igu-Chang La-Durbuk profiles are indicated inside the box. The gravity and magnetic stations are sampled with 1-2 km spacing along these profiles. The background geological map is adapted from two sources, which are indicated on the map itself.

\section{Introduction}

The presence of ophiolites in Ladakh Himalaya in different suture zones is a well known fact. However, their presence within Ladakh batholith is conjectural. Here, our closely sampled (1-2 km) gravity and magnetic data along Rumtse-Upshi-Leh-Khardung La and Rumtse-Upshi-Igu-Shakti-Chang La-Durbuk profiles are analyzed to clarify these matters.

Methodology

The regional gravity profiles in Ladakh Himalaya along this traverse (Figure 1) are processed with our algorithm (Sastry,

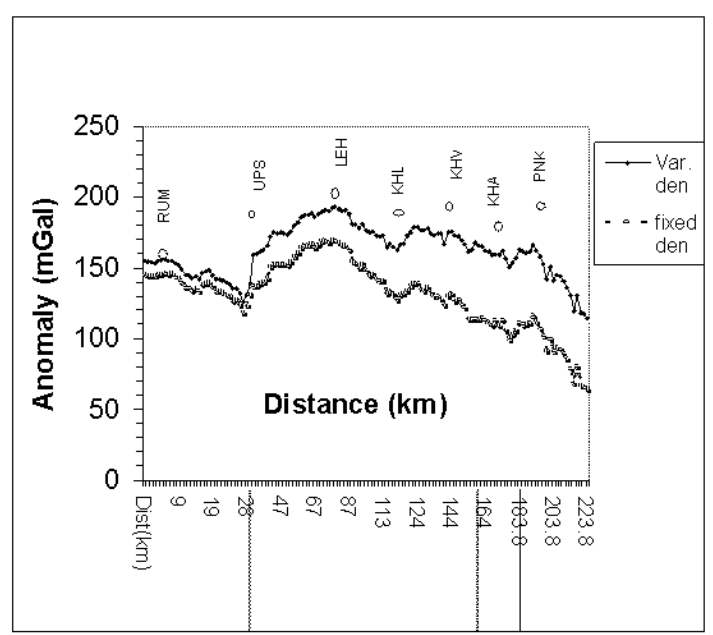

FIGURE 2. Processed gravity data along Rumte-Upshi-Igu-Leh-Khardung laPanamik using with conventional constant Bouguer density of $2.67 \mathrm{gm} / \mathrm{cc}$ and variable densities (Sastry 2005). For our analysis Bouguer anomaly with variable densities is considered. Index: IF-Indus formation, LB- Ladakh Batholith, SSZ-Shyok suture zone, KB-Karakorum batholith 


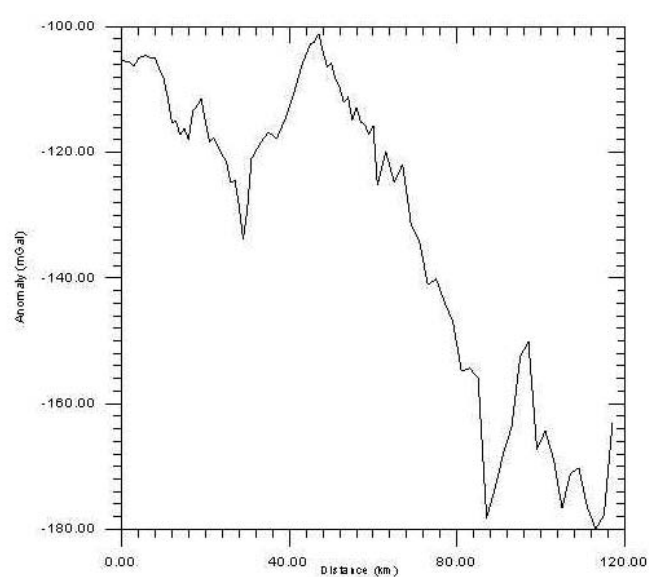

FIGURE 3. Bouguer anomaly gravity profile along Rumte-Upshi-IguShakti-Chang la-Durbuk using variable densities (Sastry 2005).

2005) utilizing 'GRAVMASTER' software of 'GEOTOOLS'. Density measurements of collected representative samples from different geological formations along the profile were utilized for this purpose. The reference Bouguer datum is mean sea level.

The processing of Rumtse-Upshi-Leh-Kardung La (Figure 2) and Rumtse-Upshi-Igu-Shakti-Chang La-Durbuk gravity profiles (Figure 3) are undertaken with two options, viz.

a) Conventional constant Bouguer density, $\mathrm{D}=2.67 \mathrm{~g} / \mathrm{cc}$ (for both Bouguer and terrain corrections)

b) Variable density for both Bouguer and terrain corrections

For our analysis, we consider gravity profiles processed with the second option. The total-field intensity data along the same profiles is processed as per norms (Figures 4, 5).

\section{Results and Discussion}

Spectral analysis of gravity data along both the profiles (Figures 6, 7) have been carried out as per norms. The inferred source of highfrequency part of the anomalies is approximately at $3 \mathrm{~km}$. Similar inference is obtained from spectral analyses of magnetic data (not included here). This has led to a quantitative interpretation of magnetic signatures.

In view of the above, the magnetic anomalies are modeled with an inclined dyke model of infinite-depth extent. The results are included in Figures 4 and 5. These results clearly suggest that the ophiolites with near vertical dips extend from shallow depths

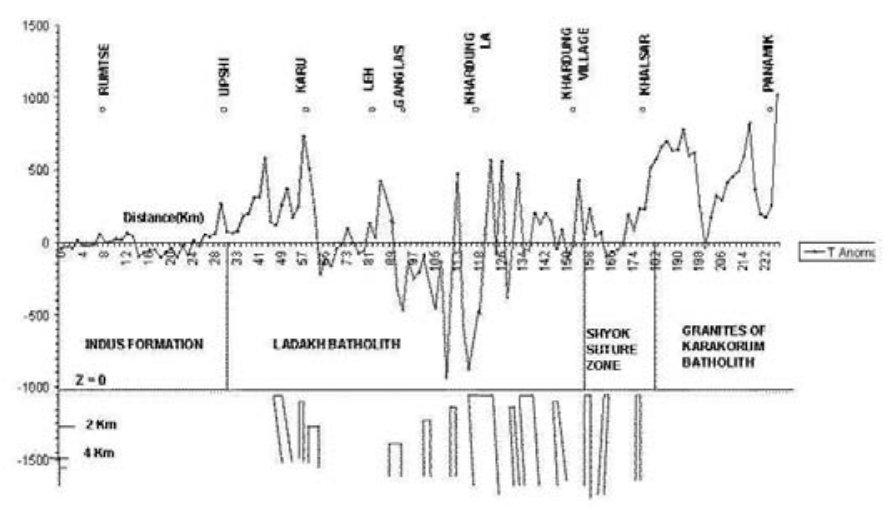

FIGURE 4. Processed magnetic anomaly along Rumte-Upshi-IguLeh-Khardung la-Panamik. Interpreted steeply dipping dykes are located within Ladakh batholith and Shyok suture zone.

$(0.25-0.4 \mathrm{~km})$ to at least up to $3.0-3.5 \mathrm{~km}$ from surface within Ladakh batholith and at Shyok suture zone.

\section{Conclusions}

The analysis of gravity and magnetic anomalies along Rumtse-UpshiLeh-Kardung La and Rumtse-Upshi-Igu-Shakti-Chang La-Durbuk profiles clearly suggest the presence of ophiolites within Ladakh batholith and Shyok Suture Zone starting from very shallow (0.25$0.4 \mathrm{~km}$ ) depths and extending at least up to $3 \mathrm{~km}$ from surface.

\section{Acknowledgements}

Authors convey their sincere thanks to Sri. DN Awasthi, Chairman, PAMC (DCS), DST, Dr. KR Gupta, Advisor, Dr. Ch. Sivaji, Scientist, DST and all concerned Advisory Committee members of DST "HIMPROBE" team for necessary support and advice. The authors also thank Ms. Neeta Chaudhary, Research Associate for assistance in processing. Thanks are also due to DST, New Delhi for sustained encouragement and financial support throughout the implementation of the DST project, of which the present piece of work is an outcome.

\section{References}

Sastry RG. 2005. Variable density option in Bouguer anomaly computation. SEG International Exposition and 75th Annual Meeting, Houston, USA, November 2005

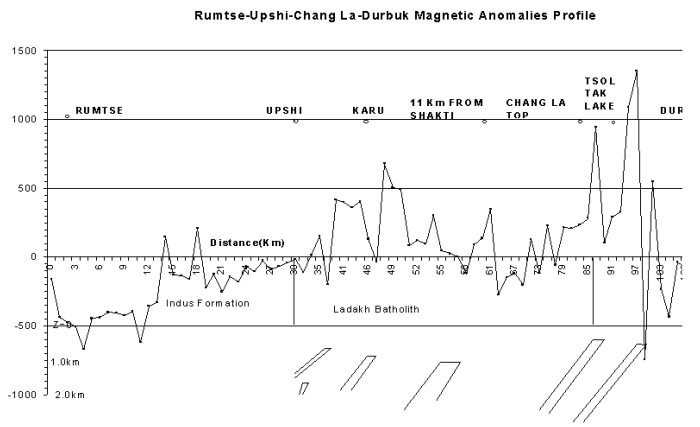

FIGURE 5. Processed magnetic anomaly along Rumte-Upshi-Igu-Shakti-Chang la - Durbuk. Interpreted steeply dipping dykes are located within Ladakh batholith and Shyok suture zone.

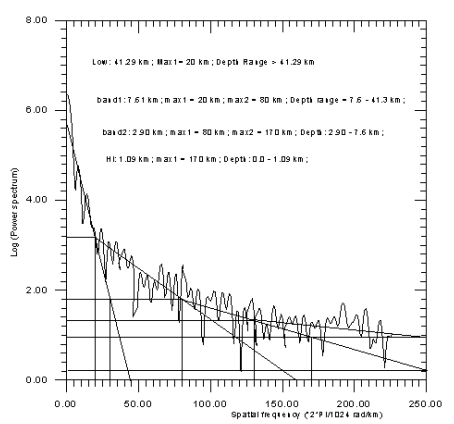

FIGURE 6. Spectral analysis of Bouguer anomaly along Rumtse-Upshi-Igu-LehKhardung la-Panamik profile. The highfrequency anomaly source extends up to at least $3.0 \mathrm{~km}$ from near surface.

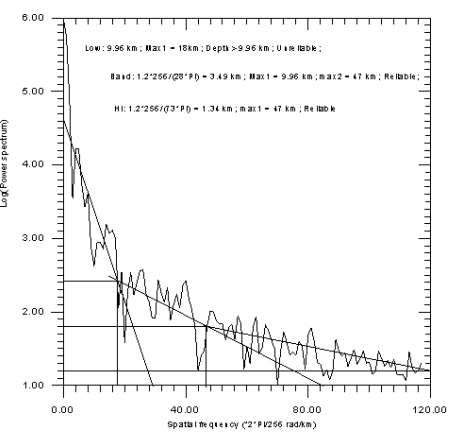

FIGURE 7. Spectral analysis of Bouguer anomaly along Rumtse-Upshi-IguShakti-Chang la-Durbuk profile. The high-frequency anomaly source extends up to at least $3.5 \mathrm{~km}$ from near surface. 